\title{
The Absolute Configuration of (+)-Oxopropaline D by Theoretical Calculation of Specific Rotation and Asymmetric Synthesis
}

\author{
Takeshi KuwadA, ${ }^{b}$ Miyako Fukui, ${ }^{a}$ Toshiyuki HatA,${ }^{a}$ Tominari Choshi, ${ }^{a}$ Junko Nobuhiro, ${ }^{a}$ \\ Yukio ONo, ${ }^{a}$ and Satoshi HiBINo ${ }^{* a}$ \\ ${ }^{a}$ Graduate School of Pharmacy and Pharmaceutical Sciences, Faculty of Pharmacy and Pharmaceutical Sciences, \\ Fukuyama University; Fukuyama, Hiroshima 729-0292, Japan: and ${ }^{b}$ Process Chemistry Laboratory, Medicinal Research \\ Laboratory, Taisho Pharmaceutical Co. Ltd.; 1-403 Yoshino-cho, Saitama, Saitama 330-8530, Japan.
}

Received July 17, 2002; accepted September 25, 2002

The specific optical rotations of $(R)$-oxopropaline $D$ calculated by two $a b$ initio MO methods were $+52 \pm 31^{\circ}$ and $+61 \pm 29^{\circ}$, respectively, and (+)-oxopropaline $D(3)$ was presumed to have an $R$-configuration. On the basis of this theoretical result, the reaction of 1 -litio- $\beta$-carboline with $(R)$-glyceraldehyde acetonide followed by oxidation with $\mathrm{MnO}_{2}$ gave $(R)$-oxopropaline $D$ acetonide (4a), which was consistent with the previously synthesized $(+)$-oxopropaline $D$ acetonide (4) in all respects. From the results of theoretical calculations and the experimental synthesis, we determined that natural (+)-oxopropaline $D(3)$ has an $R$-configuration.

Key words absolute configuration; (+)-oxopropaline D; specific optical rotation; ab initio MO method; asymmetric synthesis; $(R)-(+)$-oxopropaline D acetonide

The cytocidal $\beta$-carboline alkaloids, oxopropalines A (1), B (2), and D (3), were isolated from Streptomyces sp. G324 together with two related oxopropalines $\mathrm{E}$ and $\mathrm{G}$, which produce lavendamycin, by Abe and co-workers in 1993 (Chart 1). ${ }^{1,2)}$ This new $\beta$-carboline alkaloid possessing an acyl group and a methyl group at the 1- and 4-positions exhibits cytocidal activity. Oxopropalines A (1) and B (2) have been converted into oxopropaline D (3) by acidic methanolysis. Natural oxopropaline D (3) has positive rotation, but the absolute stereochemistry of both $\mathbf{3 a}$ and $\mathbf{3 b}$ has not been determined yet (Chart 2). Recently we reported the total syntheses of (+)- and (-)-oxopropaline D (3) by the construction of a new $\beta$-carboline framework based on a thermal electrocyclic reaction of a 1-azahexatriene system involving an indole 2,3bond, followed by enantioselective 1,2-dihydroxylation. ${ }^{3} \mathrm{We}$ described in the report ${ }^{3)}$ that absolute configurations of $(+)-3$ and (-)-3 are presumed to have $S$ and $R$, respectively, in accordance with the Sharpless rule. ${ }^{4)}$

In the present study, we describe here the determination of the absolute configuration of (+)-oxopropaline D (3). We initially estimated whether the $(R)$-oxopropaline $\mathrm{D}$ refers to either the plus or minus sign of a specific optical rotation calculated by an $a b$ initio MO method that was previously reported by the Kondru group. ${ }^{5)}$ Based on the absolute configuration estimated as $R$, an asymmetric synthesis of $(R)$-oxopropaline D acetonide (4a) was carried out in order to compare the results with those of previously synthesized (+)-oxopropaline D acetonide (4). ${ }^{3)}$

\section{Results and Discussion}

Theoretical Calculations of the Specific Optical Rotation for $(\boldsymbol{R})$-Oxopropaline $\mathbf{D}$ It is well known that the theoretical specific rotations for enantiomers show the same value and different signs. This fact indicates that only the sign of the theoretical specific rotation for $R$ - or $S$-configurations can be used to determine the absolute configuration. We attempted to determine the sign of the specific rotation for $(R)$-oxopropaline $\mathrm{D}(\mathbf{3 a})$ by theoretical calculations.

Since the specific optical rotation obtained by the theoreti-

cal calculations showed basis set and geometry dependencies, the conformational searches by MNDO-AM16) (Method A) and HF/3-21G* (Method B) methods were carried out at first. Next, the conformers showing larger probability than $1 \%$, obtained by respective conformational searches, were optimized by the HF/6-31G* ab initio MO method. The basis set dependence of the computed rotation angles was evaluated by $6-31 \mathrm{G}^{*}$ and $6-31 \mathrm{G}^{* *}$.

The specific rotations of $(R)$-oxopropaline $\mathrm{D}(\mathbf{3 a})$ obtained by all of the methods used are shown in Table 1. As shown in Table 1 , the specific rotations calculated by the $6-31 \mathrm{G}^{*}$ and $6-31 \mathrm{G}^{* *}$ basis sets were $[\alpha]_{\mathrm{D}}=+138 \pm 9^{\circ}(\operatorname{Method} \mathrm{A}),[\alpha]_{\mathrm{D}}=$

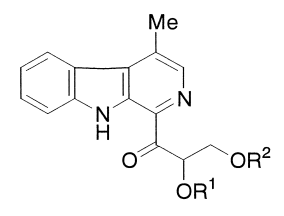

$$
\begin{aligned}
& \text { 1: oxopropaline } A \\
& \left(R^{1}=\text { rhamnose, } R^{2}=H\right) \\
& \text { 2: oxopropaline } B \\
& \left(R^{1}=H, R^{2}=\text { rhamnose }\right) \\
& \text { 3: oxopropaline } D \\
& \left(R^{1}=R^{2}=H\right) \\
& \text { 4: oxopropaline D acetonide } \\
& \left(R^{1}+R^{2}=X_{M e}^{M e}\right)
\end{aligned}
$$

Chart 1

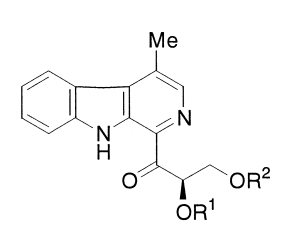

$$
\begin{aligned}
& \text { 3a: } R^{1}=R^{2}=H \\
& \text { 4a: } R^{1}+R^{2}=\chi_{M e}^{M e}
\end{aligned}
$$

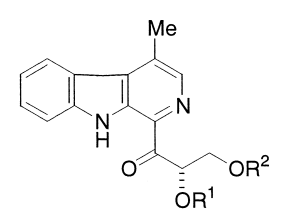

3b: $R^{1}=R^{2}=H$ 4b: $R^{1}+R^{2}=X_{M e}^{M e}$

* To whom correspondence should be addressed. e-mail: hibino@fupharm.fukuyama-u.ac.jp

Chart 2 
Table 1. Theoretical Specific Rotation Angles of $(R)$-Oxopropaline D in Methanol Solution

\begin{tabular}{ccc}
\hline \hline \multirow{2}{*}{$\begin{array}{c}\text { Basis set used in specific } \\
\text { rotational angles }\end{array}$} & \multicolumn{2}{|}{$[\alpha]_{\mathrm{D}} \pm 2 \sigma$, Conformational Search by } \\
\cline { 2 - 3 } & $\mathrm{HF} / 3-21 \mathrm{G}^{*}$ & MNDO-AM1 \\
\hline $\mathrm{HF} / 6-31 \mathrm{G}^{*}$ & $+52 \pm 31$ & $+138 \pm 9$ \\
$\mathrm{HF} / 6-31 \mathrm{G}^{* *}$ & $+61 \pm 29$ & $+139 \pm 10$ \\
\hline
\end{tabular}

All units are degree.

Table 2. Conformer's Specific Rotation Angles and Boltzmann Population of $(R)$-Oxopropaline D Optimized by HF/6-31G*

\begin{tabular}{|c|c|c|c|}
\hline \multirow{2}{*}{ ID } & \multirow{2}{*}{$\begin{array}{c}{[\alpha]_{\mathrm{D}}} \\
(\text { degree })\end{array}$} & $\mathrm{HF} / 3-21 \mathrm{G}^{* a)}$ & \multirow{2}{*}{$\begin{array}{c}\left.\text { MNDO-AM1 }^{a}\right) \\
\text { Population }^{b)}(\%)\end{array}$} \\
\hline & & Population $^{b)}(\%)$ & \\
\hline 1 & +128 & 47.5 & 70.7 \\
\hline 2 & -160 & 21.8 & \\
\hline 3 & +48 & 15.1 & 22.6 \\
\hline 4 & -92 & 10.2 & \\
\hline 5 & +23 & 1.9 & 2.9 \\
\hline 6 & -82 & 1.4 & \\
\hline 7 & +124 & 1.3 & 1.9 \\
\hline 8 & +37 & 0.8 & 1.3 \\
\hline 9 & -104 & & 0.6 \\
\hline
\end{tabular}

a) HF/3-21G* and MNDO-AM1 methods are used in conformational search. b) Boltzmann population are calculated at $T=300 \mathrm{~K}$.

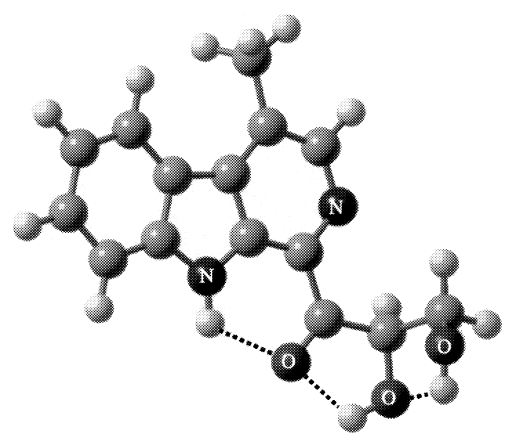

Fig. 1. Most Stable Conformer of (R)-Oxopropaline D Optimized by $\mathrm{HF} / 6-31 \mathrm{G}^{*}$

$+52 \pm 31^{\circ}\left(\right.$ Method B), and $[\alpha]_{\mathrm{D}}=+139 \pm 10^{\circ}($ Method A), $[\alpha]_{\mathrm{D}}=+61 \pm 29^{\circ}$ (Method B), respectively. These results indicate that the theoretical optical rotations calculated by Method B were identical to those of natural products, within a deviation, and the sign obtained by both methods was plus $(+)$. In addition, the theoretical values of specific rotation were not influenced by difference between the $6-31 \mathrm{G}^{*}$ and $6-31 \mathrm{G}^{* *}$ basis sets used in this study.

The theoretical specific rotation and probability of conformers optimized by Methods A and B are given in Table 2. The most stable conformers (ID 1) obtained by both methods had identical structures and formed three internal hydrogen bonds, as shown in Fig. 1. However, the number of conformers used in the Method A calculations was 6, and the number of conformers used in the Method B calculations was 8 . The probability of the ID 1 conformer $\left([\alpha]_{\mathrm{D}}=+128^{\circ}\right)$ calculated by Methods A and B was about $70 \%$ and $48 \%$, respectively, because ID 2, 4, and 6 conformers showing a minus sign of specific rotation were not found by Method A. It became ap- parent that this difference was responsible for the larger specific rotation obtained by Method A than by Method B. Therefore, the results suggested that in the conformational search, it was preferable to use the $a b$ initio MO method of a small split valence basis set. However, the sign of specific rotation for $(R)$-oxopropaline $\mathrm{D}(\mathbf{3 a})$ was plus within all calculations in this study. Taken together, the theoretical results strongly suggest that the absolute configuration at the C-11 position for natural (+)-oxopropaline $\mathrm{D}(3)$ is an $R$.

Synthesis of $(\boldsymbol{R})-(+)-O x o p r o p a l i n e ~ D$ acetonide We chose to perform an asymmetric synthesis of $(R)-(+)$-oxopropaline $\mathrm{D}$ acetonide (4a) on the basis of the above theoretical calculations. For the synthesis of $(R)-(+)$-oxopropaline $\mathrm{D}$ acetonide (4a), we initially planned a reaction of $N$ methoxymethyl(MOM)-1-bromo-4-methyl- $\beta$-carboline (7) with $(R)$-glyceraldehyde acetonide (Chart 3$)$. The required $\beta$ carboline 7 was prepared as follows. The treatment of 1-hydroxy- $N$-MOM- $\beta$-carboline $(\mathbf{5})^{3,7)}$ with phosphorus oxybromide in anisole ${ }^{8)}$ at $100{ }^{\circ} \mathrm{C}$ gave the $N$-MOM deprotected $1-$ bromo- $\beta$-carboline (6) (92\%). The required $N$-MOM-1bromo- $\beta$-carboline (7) was obtained by the reaction of 6 with chloromethyl methyl ether and sodium hydride $(53 \%)$. The $N$-MOM-1-bromo- $\beta$-carboline (7) was treated with $n$-BuLi at $-78^{\circ} \mathrm{C}$, followed by a reaction with $(R)$-glyceraldehyde acetonide $\left([\alpha]_{\mathrm{D}}+34.1^{\circ}\right.$; Lit., $\left.{ }^{9)}[\alpha]_{\mathrm{D}}+70-80^{\circ}\right)$ to give the alcohol 8 in $65 \%$ yield as a mixture of diastereomers. However, oxidation of 8 with activated manganese dioxide $\left(\mathrm{MnO}_{2}\right)$ did not provide any ketones (9). Thus, the position of interest appears to be hindered. Alternatively, the 1-bromo- $\beta$-carboline (6) was treated with potassium bis(trimethylsilyl)amide and $n$-BuLi at $-78^{\circ} \mathrm{C}$, followed by a reaction with $(R)$-glyceraldehyde acetonide to yield the alcohol (10). The crude alcohol (10) was used for the oxidation with activated $\mathrm{MnO}_{2}$ to produce the ketone $4 \mathbf{a}$ in $25 \%$ yield $\left([\alpha]_{D}+25.2^{\circ}\right)$ from 6 .

The previous synthetic ketone, $(+)$-oxopropaline D acetonide (4) derived from an asymmetric 1,2-dihydroxylation of the silyl allyl ether (11) with AD-mix- $\beta$, was available. The behavior upon HPLC and the specific rotation of the ketone 4 were identical with those of the authentic $4\left([\alpha]_{\mathrm{D}}\right.$ $\left.+20.8^{\circ}\right)$. Thus, the asymmetric synthesis of $(R)-(+)$-oxopropaline D acetonide (4a) was established in three steps. (+)-Oxopropaline D acetonide (4) was already converted into (+)-oxopropaline D (3). Consequently, the absolute stereochemistry at the $\mathrm{C}-11$ position of natural $(+)$-oxopropaline $\mathrm{D}(\mathbf{3})$ is $R$-configuration.

\section{Conclusion}

The determination of absolute configuration for natural (+)-oxopropaline D (3) was investigated by both theoretical calculations and asymmetric synthesis. The specific rotation of $(R)$-oxopropaline $\mathrm{D}$ calculated by the ab initio $\mathrm{MO}$ method revealed the plus sign within all of the theoretical calculations in this study. From this result, it was predicted that the absolute configuration of natural $(+)$-oxopropaline D is $R$. On the basis of this theoretical calculation, $(R)$-oxopropaline D acetonide (4a) was synthesized using $(R)$-glyceraldehyde acetonide as a chiral block. The observed specific rotation of compound 4a was approximately identical with that of previously synthesized (+)-oxopropaline D acetonide (4). Although an absolute stereochemistry of previously synthesized $(+)$-oxopropaline D (3) has been presumed to have 

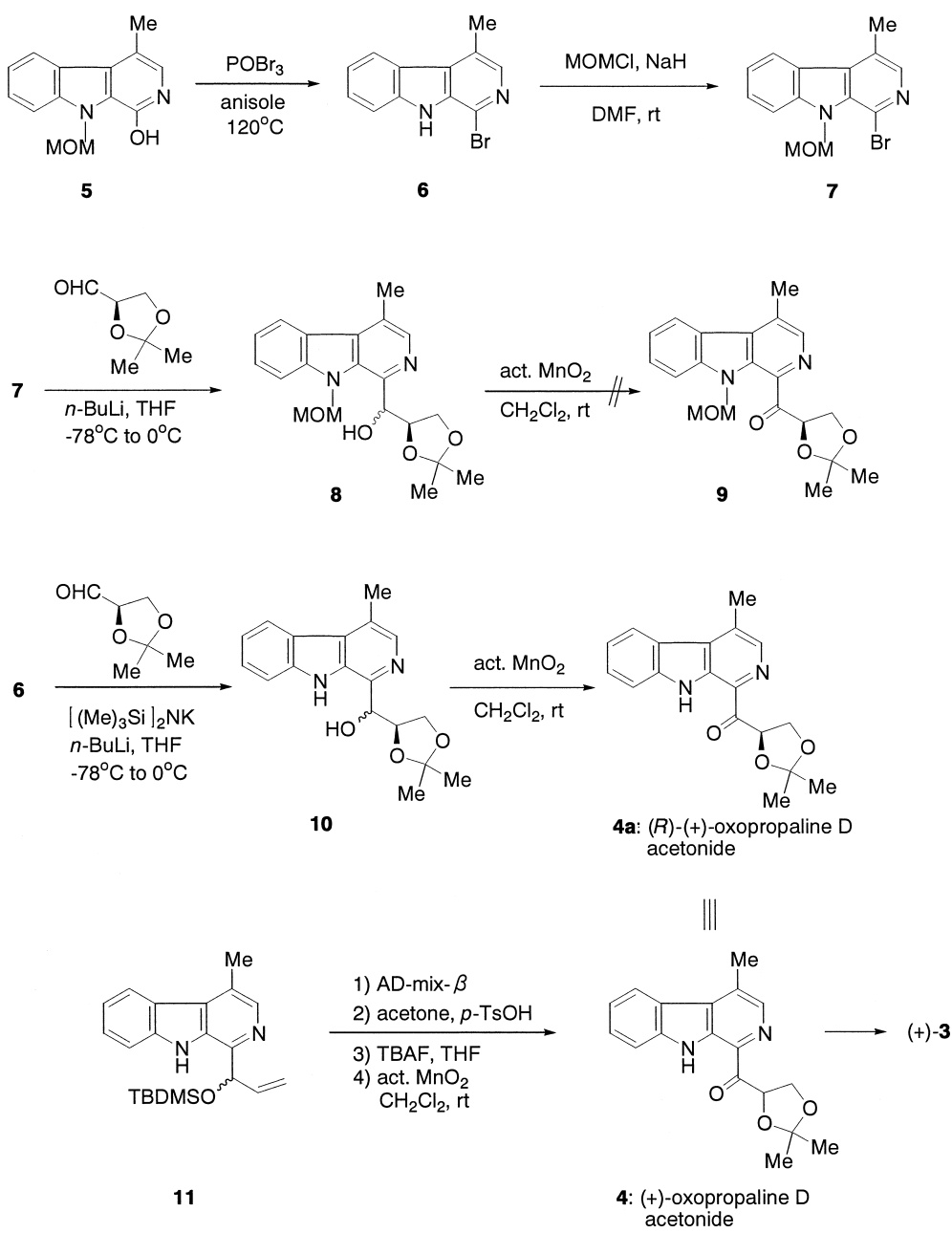

Chart 3

an $S$-configuration ${ }^{3)}$ without any steric factor by the Sharpless rule, ${ }^{4)}$ it was found that $(+)-3$ has $R$-configuration. Finally, we concluded that the absolute configuration at the C11 position in natural (+)-oxopropaline $\mathrm{D}(\mathbf{3})$ was $R$, represented by 3a and shown in Chart 2 and Fig. 1.

\section{Experimental}

Physical. Conformational Search First, a conformational search of $(R)$-oxopropaline $\mathrm{D}$ (3a) was accomplished by rotating 5 single bonds in a side chain. Next, these conformations $\left(3^{5}=243\right)$ were optimized by MNDOAM1 (Method A) and HF/3-21G* (Method B) methods. Finally, some optimized conformers showing larger Boltzmann population than $1 \%$, obtained by the respective searches, were optimized by the $a b$ initio MO method using a $6-31 \mathrm{G}^{*}$ basis set, and the specific rotations of these optimized conformers were calculated by $\mathrm{HF} / 6-31 \mathrm{G}^{*}$ and $\mathrm{HF} / 6-31 \mathrm{G}^{* *}$. All optimizations mentioned above were carried out with the Gaussian 98 ab initio program. ${ }^{10)}$

Calculation of Specific Rotation The specific rotation $[\alpha]^{11,12)}$ of a chiral molecule was obtained from the frequency $v$ as:

$$
[\alpha]=\frac{28800 \pi^{2} N_{\mathrm{A}} v^{2}}{c^{2} M} \gamma_{\mathrm{S}} \beta
$$

where $N_{\mathrm{A}}$ is Avogadro's constant, $c$ is the light velocity, $\gamma_{\mathrm{s}}$ is the solvent effect frequently approximated using the Lorentz factor $\left(\gamma_{\mathrm{s}}=\left(n^{2}+2\right) / 3\right.$; $n$ : the refractive index of the medium). $\beta=\operatorname{Tr}\left[\beta_{\alpha \beta}\right] / 3=\left[\beta_{\mathrm{xx}}+\beta_{\mathrm{yy}}+\beta_{\mathrm{zz}}\right] / 3$, where $\beta_{\alpha \beta}$ is the electric dipole-magnetic dipole polarizability. $\beta_{\alpha \beta}$ is estimated from $a b$ initio method using linear response method at the Hartree Fock level ${ }^{13)}$ proposed by Helgaker et al. In this paper, the calculation of $\beta_{\alpha \beta}$ at the sodium D-line $(589.3 \mathrm{~nm})$ was carried out with the DALTON program ${ }^{14)}$ using Helgaker et al. algorithms. The value of the refractive index in the Lorentz fac- tor adopted 1.3285 of the methanol medium. The two basis sets using the calculation of specific rotation were $6-31 \mathrm{G}^{*}$ and $6-31 \mathrm{G}^{* *}$. The final specific rotation was determined by Boltzmann weighting of specific rotations for all adopted conformers. ${ }^{5)}$

Organic. General Melting points were measured on a Yanagimoto micro-melting point apparatus MP-500D and are uncorrected. Infrared spectra (IR) were recorded on a Shimadzu FTIR-8500 spectrophotometer. Proton nuclear magnetic resonance spectra $\left({ }^{1} \mathrm{H}-\mathrm{NMR}\right)$ were taken with a JEOLAL300 instrument using tetramethylsilane as an internal standard. Mass spectra (MS) were determined by a Shimadzu QP5050 mass spectrometer. All air-sensitive reactions were run under nitrogen atmosphere. Silica gel (60-100 mesh, Merck Art 7734) was used for column chromatography. Identification of chiral material was carried out by HPLC (CHIRALPAK $\mathrm{AD})$ using iso-PrOH-hexane $(4: 1)$ as an eluent.

1-Bromo-4-methyl-9H-pyrido[3,4-b]indole (6) A mixture of $\beta$-carboline $\mathbf{5}^{3,7)}(350 \mathrm{mg}, 1.45 \mathrm{mmol})$ and phosphorus oxybromide $(2.9 \mathrm{~g}$, $10.1 \mathrm{mmol})$ in dry anisole $(3 \mathrm{ml})$ was heated at $120^{\circ} \mathrm{C}$ for $4 \mathrm{~h}$. After cooling to the ambient temperature, the reaction mixture was poured into an icewater. The mixture was basified with $10 \%$ aqueous $\mathrm{Na}_{2} \mathrm{CO}_{3}$. The resulting mixture was extracted with EtOAc. The EtOAc layer was washed with brine, dried over $\mathrm{Na}_{2} \mathrm{SO}_{4}$, and concentrated. The residue was recrystallized from EtOAc-hexane to give the 1-bromo- $\beta$-carboline 6 (348 mg, 92\%). mp $150-$ $152{ }^{\circ} \mathrm{C} .{ }^{1} \mathrm{H}-\mathrm{NMR}\left(\mathrm{CDCl}_{3}\right): \delta: 2.78(\mathrm{~s}, 3 \mathrm{H}), 7.26-7.38(1 \mathrm{H}, \mathrm{m}), 7.58-7.62$ $(2 \mathrm{H}, \mathrm{m}), 8.01(1 \mathrm{H}, \mathrm{s}), 8.16(1 \mathrm{H}, \mathrm{d}, J=8.1 \mathrm{~Hz}), 8.46(1 \mathrm{H}, \mathrm{br} \mathrm{s})$. MS: $m / z: 262$ and, $260\left(\mathrm{M}^{+}\right)$. Anal. Calcd for $\mathrm{C}_{12} \mathrm{H}_{9} \mathrm{BrN}_{2}: \mathrm{C}, 55.20 ; \mathrm{H}, 3.47 ; \mathrm{N}, 10.73$. Found: C, 55.32; H, 3.50; N, 10.71.

1-Bromo- $N$-(methoxymethyl)-4-methyl-9H-pyrido[3,4-b]indole (7) A solution of 1-bromo- $\beta$-carboline $\mathbf{6}(430 \mathrm{mg}, 1.65 \mathrm{mmol})$ in $N, N$-dimethylformamide (DMF) $(15 \mathrm{ml})$ was added to a suspension of $60 \% \mathrm{NaH}(79 \mathrm{mg}$, $1.98 \mathrm{mmol})$ in DMF $(10 \mathrm{ml})$ under cooling with ice-water. After stirring at the same temperature for $30 \mathrm{~min}$, a solution of chloromethyl methyl ether 
$(150 \mu 1,1.98 \mathrm{mmol})$ in DMF $(1 \mathrm{ml})$ was added to the mixture. After stirring at room temperature for $12 \mathrm{~h}$, the reaction mixture was quenched with an aqueous (saturated) $\mathrm{NH}_{4} \mathrm{Cl}$ solution. The mixture was extracted with EtOAc. The EtOAc layer was washed with brine, dried over $\mathrm{Na}_{2} \mathrm{SO}_{4}$, and concentrated. The residue was purified by column chromatography (silica gel, $20 \mathrm{~g}$ ) using EtOAc-hexane (1:9) as an eluent to give the $N$-MOM- $\beta$-carboline 7 (265 mg, 53\%). mp $91-93{ }^{\circ} \mathrm{C}$ (EtOAc-hexane). ${ }^{1} \mathrm{H}-\mathrm{NMR}\left(\mathrm{CDCl}_{3}\right) \delta: 2.81$ $(3 \mathrm{H}, \mathrm{s}), 3.35(3 \mathrm{H}, \mathrm{s}), 6.20(2 \mathrm{H}, \mathrm{s}), 7.36-7.41(1 \mathrm{H}, \mathrm{m}), 7.62-7.71(2 \mathrm{H}, \mathrm{m})$, $8.05(1 \mathrm{H}, \mathrm{s}), 8.21(1 \mathrm{H}, \mathrm{d}, J=7.3 \mathrm{~Hz})$. MS: $m / z$ : 306 and, $304\left(\mathrm{M}^{+}\right)$. Anal. Calcd for $\mathrm{C}_{14} \mathrm{H}_{13} \mathrm{BrN}_{2} \mathrm{O}$ : C, 55.10; H, 4.29; N, 9.18. Found: C, 55.25; H $4.40 ; \mathrm{N}, 9.07$.

1-(Hydroxy-2,3-isopropylidenepropyl)- $N$-(methoxymethyl)-4-methyl9H-pyrido[3,4-b]indole (8) $n$-BuLi $(2.47 \mathrm{~mol} / 1$ in hexane, $0.33 \mathrm{ml}$, $0.82 \mathrm{mmol})$ was added to a solution of 1 -bromo- $N$-(MOM)- $\beta$-carboline 7 $(50 \mathrm{mg}, 0.16 \mathrm{mmol})$ in tetrahydrofuran $(\mathrm{THF})(2 \mathrm{ml})$ at $-78^{\circ} \mathrm{C}$. After stirring at the same temperature for $30 \mathrm{~min}$, a solution of $(R)$-glyceraldehyde acetonide $(146 \mathrm{mg}, 1.12 \mathrm{mmol})$ in THF $(2 \mathrm{ml})$ was added to the reaction mixture at the same temperature. The mixture was allowed to warm to room temperature and was stirred for $12 \mathrm{~h}$. The mixture was quenched with an aqueous (saturated) $\mathrm{NH}_{4} \mathrm{Cl}$ solution. The mixture was extracted with EtOAc. The EtOAc layer was washed with brine, dried over $\mathrm{Na}_{2} \mathrm{SO}_{4}$, and concentrated. The residue was purified by column chromatography (silica gel, $20 \mathrm{~g}$ ) using EtOAc-hexane (1:9) as an eluent to give the oily alcohol 8 (37 mg, $65 \%$ ). IR (neat) $v: 3000 \mathrm{~cm}^{-1} ;{ }^{1} \mathrm{H}-\mathrm{NMR}\left(\mathrm{CDCl}_{3}\right) \delta: 1.23-1.50(6 \mathrm{H}, \mathrm{s} \times 4$, $\left.\mathrm{CH}_{3} \times 4 \times 1 / 2\right), 2.85(3 / 2 \mathrm{H}, \mathrm{s}), 2.86(3 / 2 \mathrm{H}, \mathrm{s}), 3.26(3 / 2 \mathrm{H}, \mathrm{s}), 3.29(3 / 2 \mathrm{H}, \mathrm{s})$, $3.60-4.35(4 \mathrm{H}, \mathrm{m}), 5.52(1 / 2 \mathrm{H}, \quad$ brd, $J=6.6 \mathrm{~Hz}), 5.58(1 / 2 \mathrm{H}, \quad$ brd, $J=5.9 \mathrm{~Hz}), 5.74(1 / 2 \mathrm{H}, \mathrm{d}, J=12 \mathrm{~Hz}), 5.90(1 / 2 \mathrm{H}, \mathrm{d}, J=12 \mathrm{~Hz}), 6.06(1 / 2 \mathrm{H}, \mathrm{d}$, $J=12 \mathrm{~Hz}), 6.24(1 / 2 \mathrm{H}, \mathrm{d}, J=12 \mathrm{~Hz}), 7.30-7.37(1 \mathrm{H}, \mathrm{m}), 7.57-7.68(2 \mathrm{H}$, m), 8.22-8.28 (2H, m); MS m/z: $356\left(\mathrm{M}^{+}\right)$. Anal. Calcd for $\mathrm{C}_{20} \mathrm{H}_{24} \mathrm{~N}_{2} \mathrm{O}_{4}: \mathrm{C}$, 67.40; H, 6.79; N, 7.86. Found: C, 67.58; H, 6.96; N, 7.65.

1-(2,3-Isopropylidenepropionyl)-4-methyl-9H-pyrido[3,4-b]indole (10) A solution of 1-bromo- $\beta$-carboline $6(110 \mathrm{mg}, 0.42 \mathrm{mmol})$ in THF $(3 \mathrm{ml})$ was added to a solution of potassium bis(trimethylsilyl)amide $(0.5 \mathrm{~mol} / 1$ in THF, $0.84 \mathrm{ml}, 0.42 \mathrm{mmol})$ in THF $(2 \mathrm{ml})$ at $-78^{\circ} \mathrm{C}$. After stirring at the same temperature for $1 \mathrm{~h}, n$-BuLi $(2.47 \mathrm{~mol} / 1$ in hexane, $1.2 \mathrm{ml}, 2.95 \mathrm{mmol})$ was added, and the mixture was stirred for an additional $1 \mathrm{~h} .(R)$-Glyceraldehyde acetonide $(822 \mathrm{mg}, 6.32 \mathrm{mmol})$ in THF $(3 \mathrm{ml})$ was added to the reaction mixture at the same temperature. The mixture was allowed to warm to room temperature, stirred for $12 \mathrm{~h}$, and quenched with an aqueous (saturated) $\mathrm{NH}_{4} \mathrm{Cl}$ solution. The mixture was extracted with EtOAc. The EtOAc layer was washed with brine, dried over $\mathrm{Na}_{2} \mathrm{SO}_{4}$, and concentrated. The residue was purified by column chromatography (silica gel, $20 \mathrm{~g}$ ) using EtOAc-hexane $(1: 9)$ as an eluent to give the crude alcohol 10. A suspension of the alcohol 10 and active $\mathrm{MnO}_{2}(2.6 \mathrm{~g})$ in $\mathrm{CH}_{2} \mathrm{Cl}_{2}(10 \mathrm{ml})$ was stirred at room temperature for $12 \mathrm{~h}$. The reaction mixture was filtered though Celite and the Celite was washed with $\mathrm{CH}_{2} \mathrm{Cl}_{2}$. The combined filtrates were concentrated under reduced pressure, and then the residue was purified by column chromatography (silica gel, $20 \mathrm{~g}$ ) using EtOAc-hexane (1:9) as an eluent to give the $(R)$-oxopropaline D acetonide $4 \mathrm{a}(33 \mathrm{mg}, 25 \%)$. mp 160 $162^{\circ} \mathrm{C}\left(\mathrm{Et}_{2} \mathrm{O}\right) .[\alpha]_{\mathrm{D}}^{24}+25.2^{\circ}(c=0.4, \mathrm{MeOH})$. IR $(\mathrm{KBr}): v: 2950,1670$ $\mathrm{cm}^{-1} .{ }^{1} \mathrm{H}-\mathrm{NMR}\left(\mathrm{CDCl}_{3}\right) \delta: 1.54(3 \mathrm{H}, \mathrm{s}), 1.62(3 \mathrm{H}, \mathrm{s}), 2.92(3 \mathrm{H}, \mathrm{s}), 4.11$ $(1 \mathrm{H}, \mathrm{dd}, J=6.2,8.2 \mathrm{~Hz}), 4.75(1 \mathrm{H}, \mathrm{t}, J=8.2 \mathrm{~Hz}), 5.98(1 \mathrm{H}, \mathrm{dd}, J=6.2$,
$8.2 \mathrm{~Hz}), 7.33-7.39(1 \mathrm{H}, \mathrm{m}), 7.60-7.62(2 \mathrm{H}, \mathrm{m}), 8.20(1 \mathrm{H}, \mathrm{d}, J=8.1 \mathrm{~Hz})$, $8.27(1 \mathrm{H}, \mathrm{s}), 10.28\left(1 \mathrm{H}\right.$, br s). MS (CI): $m / z: 311\left(\mathrm{M}^{+}+1\right)$. Anal. Calcd for $\mathrm{C}_{18} \mathrm{H}_{18} \mathrm{~N}_{2} \mathrm{O}_{3}$ : C, 69.66; H, 5.85; N, 9.03. Found: C, 69.74; H, 5.90; N, 8.91.

Acknowledgements This work was partly supported by The Ministry of Education, Science, Sports, and Culture of Japan [Grant-in-Aid for Scientific Research (11672131)].

\section{References and Notes}

1) Abe N., Nakakita Y., Nakamura T., Enoki N., Uchida H., Takeo S., Munekata M., J. Antibiot., 46, 1672-1677 (1993).

2) Abe N., Enoki N., Nakakita Y., Uchida H., Nakamura T., Munekata M., J. Antibiot., 46, 1678-1686 (1993).

3) Choshi T., Kuwada T., Fukui M., Matsuya Y., Sugino E., Hibino S., Chem. Pharm. Bull., 48, 108-113 (2000)

4) Sharpless K. B., Amberg W., Bennani Y. L., Crispino G. A., Hartung J., Jeong K.-S., Kwong H.-L., Wang Z.-M., Xu D., Zhang X.-L., J. Org. Chem., 57, 2768-2771 (1992).

5) Kondru R. K., Wipf P., Bertan D. N., J. Am. Chem. Soc., 120, 2204 2205 (1998).

6) Dewar M. J. S., Zoebisch E. G., Healy E. F., Stewart J. J. P., J. Am. Chem. Soc., 107, 3902-3909 (1985).

7) Choshi T., Matsuya Y., Okida M., Inada K., Sugino E., Hibino S., Tetrahedron Lett., 39, 2341-2344 (1998).

8) Hildebrand D., Bracher F., Tetrahedron, 43, 12329-12336 (1994).

9) Schmidt R. C., Bryant J., Org. Synth., 72, 6-13 (1995).

10) Gaussian 98, Revision A.11, Frisch M. J., Trucks G. W., Schlegel H. B., Scuseria G. E., Robb M. A., Cheeseman J. R., Zakrzewski V. G., Montgomery J. A., Stratmann Jr., R. E., Burant J. C., Dapprich S., Millam J. M., Daniels A. D., Kudin K. N., Strain M. C., Farkas O., Tomasi J., Barone V., Cossi M., Cammi R., Mennucci B., Pomelli C., Adamo C., Clifford S., Ochterski J., Petersson G. A., Ayala P. Y., Cui Q., Morokuma K., Salvador P., Dannenberg J. J., Malick D. K., Rabuck A. D., Raghavachari K., Foresman J. B., Cioslowski J., Ortiz J. V., Baboul A. G., Stefanov B. B., Liu G., Liashenko A., Piskorz P., Komaromi I., Gomperts R., Martin R. L., Fox D. J., Keith T., Al-Laham M. A., Peng C. Y., Nanayakkara A., Challacombe M., Gill P. M. W., Johnson B., Chen W., Wong M. W., Andres J. L., Gonzalez C., Head-Gordon M., Replogle E. S., Pople J. A., Gaussian, Inc., Pittsburgh PA, 2001.

11) Rosenfeld L. Z., Physik, 52, 161-174 (1928).

12) Eryring H., Walter J., Kimball G. E., "Quantum Chemistry," John Wiley, New York, 1944, Chap. 17.

13) Helgaker T., Ruud K., Bak K. L., Jørgensen P., Olsen J., Faraday Discuss., 99, 165-180 (1994).

14) Dalton, a molecular electronic structure program, Release 1.2 (2001), written by Helgaker T., Jensen H. J. Aa., Jørgensen P., Olsen J., Ruud K., Ågren H., Auer A. A., Bak K. L., Bakken V., Christiansen O., Coriani S., Dahle P., Dalskov E. K., Enevoldsen T., Fernandez B., Hättig C., Hald K., Halkier A., Heiberg H., Hettema H., Jonsson D., Kirpekar S., Kobayashi R., Koch H., Mikkelsen K. V., Norman P., Packer M. J., Pedersen T. B., Ruden T. A., Sanchez A., Saue T., Sauer S. P. A., Schimmelpfennig B., Sylvester-Hvid K. O., Taylor P. R., Vahtras O. 